Научная статья

УДК $314.7,504.03$

DOI: $10.17213 / 2075-2067-2021-5-128-141$

\title{
МЕТОДОЛОГИЧЕСКИЕ ПРОБЛЕМЫ КОЛИЧЕСТВЕННЫХ ОЦЕНОК И ПРОГНОЗОВ КЛИМАТИЧЕСКОЙ МИГРАЦИИ
}

\author{
Евгения Михайловна Моисеева
}

\begin{abstract}
Институт демографических исследований
Федерального научно-исследовательского социологического центра РАН, Москва, Россия evgeniyamoiseeva@mail.ru, ОRСID: 0000-0001-7571-2369, AuthorID РИНЦ: 665294
\end{abstract}

Аннотация. Цель исследования. Исследование посвящено обзору и критическому анализу имеющихся на сегодняшний день оценок и прогнозов численности климатических мигрантов, а также методологических подходов, на которых они основаны.

Методология исследования. Рассматриваются базы первичных и вторичных статистических данных по климатической миграчии, а также библиографические базы, научные статьи, монографии и доклады по этой теме. Для их анализа применяются стандартные общенаучные методы с иеелью получения качественной оценки достоинств и недостатков, перспектив и ограничений имеющихся эмпирических данных, методов их сбора и обработ-

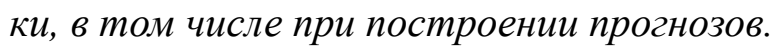

Результаты исследования. Выявлены особенности климатической миграчии и ее статистического учета, затрудняющие получение объективной картины масштабов и направлений данных миграционных потоков на основе эмпирических данных. Определены сильные и слабые стороны различных методологических подходов к косвенной оценке численности климатических мигрантов и ее прогнозам.

Перспективы исследования. Проведенный анализ показал, что в иелях уточнения количественных оценок климатической миграчии необходимо с одной стороны совершенствование систем и методов сбора первичных статистических данных и комплексное применение различных методов ее изучения с другой стороны, поскольку ни один из имеющихся на сегодняшний день методологических подходов не свободен от своих недостатков. Названы наиболее перспективные направления для работы в данном направлении.

Ключевые слова: изменение климата, миграция, климатическая миграция, статистический учет, количественные оценки, методология

Для цитирования: Моисеева Е. М. Методологические проблемы количественных оченок и прогнозов климатической миграции // Вестник Южно-Российского государственного технического университета. Серия: Социально-экономические науки. 2021. T. 14, №5. C. 128-141. http://dx.doi.org/10.17213/2075-2067-2021-5-128-141.

Благодарности: исследование выполнено при финансовой поддержске РФФИ в рамках научного проекта №20-310-90021.

(C) Моисеева Е. М., 2021 
Original article

\title{
METHODOLOGICAL PROBLEMS OF QUANTITATIVE ESTIMATES AND FORECASTS OF CLIMATE MIGRATION
}

\author{
Evgeniya M. Moiseeva
}

\author{
Institute of Demographic Research of the Federal Research Sociological Center \\ of the Russian Academy of Sciences, Moscow, Russia \\ evgeniyamoiseeva@mail.ru, ORCID: 0000-0001-7571-2369, AuthorID RSCI: 665294
}

\begin{abstract}
The purpose of the study. The article is dedicated to a review and critical analysis of the currently existing quantitative estimates and forecasts of climate migration, as well as the methodological approaches which produced them.

The methodological basis of the study. The study considers databases of primary and secondary statistical data on climate migration, as well as bibliographic databases, research papers, monographs and reports on this issue. For their analysis, standard general scientific methods are applied in order to obtain a qualitative assessment of the advantages and disadvantages, prospects and limitations of the available empirical data, as well as methods of their collection and processing, including for making forecasts.

The results of the study. The article reveals the features of climate migration and its statistical accounting, which make it difficult to obtain an objective picture of the scales and directions of such migration flows based on empirical data. The authors outline the strengths and weaknesses of different methodological approaches to the indirect quantitative estimates of climate migration and its forecasts.
\end{abstract}

The prospects for further research. The analysis showed that in order to improve the assessments of climate migration, it is necessary, on the one hand, to further develop the systems and methods for collecting primary statistical data and, on the other hand, to apply complex methods of its study, since none of the currently existing approaches is free from their shortcomings. The most promising areas for work in this direction are identified.

Keywords: climate change, migration, climate migration, statistical accounting, quantitative estimates, methodology

For citation: Moiseeva E. M. Methodological problems of quantitative estimates and forecasts of climate migration // Bulletin of the South Russian State Technical University. Series: Socio-economic Sciences. 2021; 14(5): 128-141. (In Russ.). http://dx.doi.org/10.17213/2075-2067-2021-5128-141.

Acknowledgments: the reported study was funded by RFBR according to the research project №20-310-90021.

Введение. В последние годы тема массовых миграций населения, вызванных глобальным изменением климата, привлекает всё больше внимания не только со стороны ученых и международных организаций, но также и широкой общественности. Свидетельством тому можно назвать всё возраста- ющее количество публикаций по данной проблеме в средствах массовой информации, где зачастую рисуются пугающие апокалиптические картины бегства сотен миллионов человек от «гнева природы», особенно из таких климатически неблагоприятных регионов, как Африка южнее Сахары, Латинская Аме- 
рика, Южная, Юго-Восточная и Центральная Азия ${ }^{1}$. Предсказывается также, что эта угроза не минует и Россию ${ }^{2}$. Причиной такой общественной обеспокоенности во многом стали количественные оценки и прогнозы численности климатических мигрантов, выдвигаемые учеными и общественными организациями. Максимальная называемая в различных источниках цифра - 1,5 миллиарда вынужденных переселенцев к 2050 г. $^{3}$. При этом пресса порой распространяет информацию без ссылок на какой-либо конкретный источник, а ученые в своих работах не приводят подробного изложения методологии, на которой были основаны их выводы. К сожалению, эти методологические пробелы зачастую не вызывают вопросов, которые они должны вызывать. Причиной тому, вероятно, является благое намерение привлечь внимание общества к проблемам глобального потепления и заставить правящие круги принять надлежащие меры. Мигранты при этом представляются как «человеческое лицо изменения климата», что является в большей мере политизированным подходом, который уже подвергался критике со стороны академических исследователей [1].

Однако более или менее точные оценки настоящей и будущей численности мигрантов, чье переселение спровоцировано негативными последствиями изменения климата, необходимы для принятия эффективных управленческих решений в области миграционной, экологической и социально-экономической политики стран. Меры, основанные на неверных данных, могут привести к нежелательным результатам. В то же время немалая часть распространяемой сегодня по разным каналам информации происходит из «серой литературы», которая выпускается всевозможными общественными организациями и не проходила стандартных научных процедур [напр., 2; 3]. Целью нашего исследования является обзор и критический анализ имеющихся на сегодняшний день оценок и прогнозов численности климатических мигрантов, а также методологических подходов, на которых они основаны.

Материалы и методы исследования. В данной работе рассматриваются базы первичных и вторичных статистических данных по климатической миграции, обзор которых приводится ниже, а также библиографические базы, научные статьи, монографии и доклады по этой теме. Для их анализа применяются стандартные общенаучные методы с целью получения качественной оценки достоинств и недостатков, перспектив и ограничений имеющихся эмпирических данных, методов их сбора и обработки, в том числе при построении прогнозов.

Под климатической миграцией понимается, согласно определению Международной организации по миграции (МОМ), «перемещение лиц или групп лиц, которые главным образом по причинам внезапного или прогрессирующего изменения окружающей среды, вызванного изменением климата, вынуждены покинуть свое постоянное место жительства или решили сделать это временно или безвозвратно в пределах государства или за пределами его границ» [4, c. 31]. Такое определение используется нами как рабочее, поскольку на настоящий момент не существует широкого научного консенсуса относительно данного термина. Также он не имеет юридической силы в международ-

1 Дуэль А. Как избежать катастрофического для людей изменения климата на планете [Электронный ресурс] // Российская газета. 18.08.2021. URL: https://rg.ru/2021/08/18/kak-izbezhat-katastroficheskogo-dlia-liudejizmeneniia-klimata-na-planete.html (дата обращения: 20.08.2021); Миру предрекли беспрецедентный наплыв мигрантов из Африки и Южной Америки [Электронный ресурс] // Интернет-издание «Лента.ру». 19.08.2021. URL: https://enta.ru/news/2021/08/19/global_migration/ (дата обращения: 20.08.2021); Миллиард человек в ближайшие 50 лет могут стать «климатическими мигрантами» [Электронный ресурс] // Интернет-издание «Медуза». 13.05.2020. URL: https://meduza.io/feature/2020/05/13/milliard-chelovek-v-blizhayshie-50-let-mogut-statklimaticheskimi-migrantami (дата обращения: 20.08.2021).

2 России предрекли наплыв мигрантов из-за изменения климата [Электронный ресурс] // Интернет-издание «Лента.pу». 04.06.2021. URL: https://lenta.ru/news/2021/06/04/budet_zharko/ (дата обращения: 20.08.2021); Потепление климата: в Россию хлынут мигранты с засыхающего юга [Электронный ресурс] // Сайт телеканала «Вести». 13.04.2021. URL: https://www.vesti.ru/article/2549949 (дата обращения: 20.08.2021).

3 Climate Change Will Create 1.5 Billion Migrants by 2050 and We Have No Idea Where They'll Go [Электронный ресурс] // Сайт журнала «VICE». 12.09.2019. URL: https:/www.vice.com/en/article/59n9qa/climate-changewill-create-15-billion-migrants-by-2050-and-we-have-no-idea-where-theyll-go (дата обращения: 12.07.2021). 
ном или национальных законодательствах. Данная трактовка понятия климатической миграции является максимально расширенной и охватывает любые перемещения населения, прямо или косвенно вызванные природно-климатическими и экологическими факторами.

Результаты. Первое, что обращает на себя внимание, - как в ранних работах, посвященных климатической миграции, так и в более поздних исследованиях количественные оценки и прогнозы значительно разнятся (см. таблицу 1). Это еще раз свидетельствует о том, что единый методологический подход к таким оценкам не был выработан и по сей день.

До конца 2000-х годов какой-либо агрегированной базы данных по климатической миграции не существовало, поэтому все глобальные оценки, публикуемые исследователями, были косвенными и так или иначе опирались на эмпирические исследования по отдельным регионам (case studies), а также данные о численности и размещении населения и климатические данные (о температурах, влажности, уровне моря и т.д.). Затем появились базы данных о вынужденной миграции из-за природных катастроф, о которых будет подробнее сказано ниже, однако целостные системы статистического учета климатической миграции не созданы и по сей день. Тому можно выделить несколько причин.

1. Прежде всего, отсутствует общепринятое определение климатической миграции, и, следовательно, не может быть однозначно определена сама единица статистического учета, наблюдения и регистрации. Поскольку объект исследования не имеет универсальных четко установленных границ, то невозможно создание единого понятийного аппарата и разработка единой методологии в статистической практике. Немногие страны, в той или иной форме осуществляющие учет климатических и экологических мигрантов (в их числе и Россия ${ }^{4}$ ), пользуются разными методологиями, поэтому национальные данные не сопоставимы.
2. В случае внезапных природных катастроф не вызывает сомнения, что именно послужило причиной перемещения населения, однако в случае медленно прогрессирующих изменений окружающей среды зачастую сложно установить, являлись ли они основной причиной миграции [13], сложно отделить климатическую миграцию от экономической.

3. Статистический учет легко осуществим в случае организованной миграции: экстренной эвакуации из-за стихийных бедствий или плановых переселений в случае, например, повышения уровня моря или при реализации экологических проектов. Однако в случае неорганизованных переселений получить данные о численности климатических мигрантов возможно только при условии их самостоятельного сообщения по каналам регистрации о причинах перемещения.

4. Статистический учет охватывает только новые перемещения (migrant flow). Не выработаны методы продолжительного наблюдения, которое позволяло бы получить данные о дальнейшей судьбе климатических мигрантов: их возвращении к прежнему месту жительства или последующем переезде на другую территорию. Таким образом, недоступны точные данные о контингенте климатических мигрантов (migrant stock) в том или ином регионе. Работу в этом направлении с 2019 г. начал проводить Internal Displacement Monitoring Center (IDMC) ${ }^{5}$. Даже в случае организованных миграций не ведется учет демографических и социально-экономических характеристик климатических мигрантов: не доступна информация об их поле, возрасте, образовании, уровне дохода и т.д. Это не позволяет на основе статистических данных получить полную картину механизмов и последствий климатической миграции или портрет типичного климатического мигранта.

5. Первичным источником статистических данных о климатической миграции служат, главным образом, отчеты местных властей или неправительственных организа-

4 Численность и миграция населения Российской Федерации. Статистические сборники [Электронный ресурс] // Росстат. URL: https://rosstat.gov.ru/compendium/document/13283 (дата обращения: 08.08.2021).

5 Global Report on Internal Displacement 2021 [Electronic resource] // Internal Displacement Monitoring Center. URL: https://www.internal-displacement.org/global-report/grid2021/ (date accessed: 15.07.2021). 


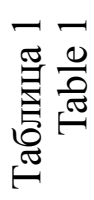

\begin{tabular}{|c|c|c|c|c|c|c|c|c|c|c|}
\hline \multirow{4}{*}{ 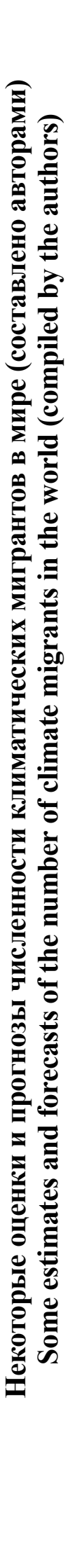 } & 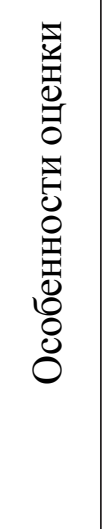 & \multicolumn{3}{|c|}{ 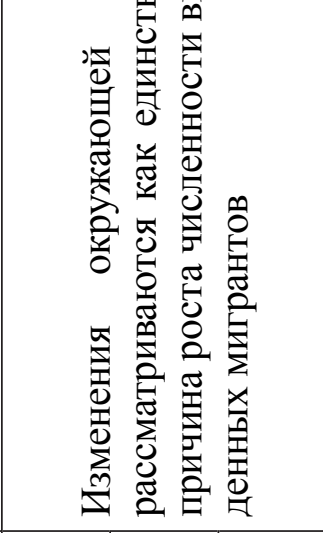 } & 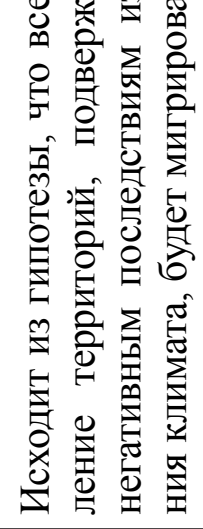 & \multicolumn{3}{|c|}{ 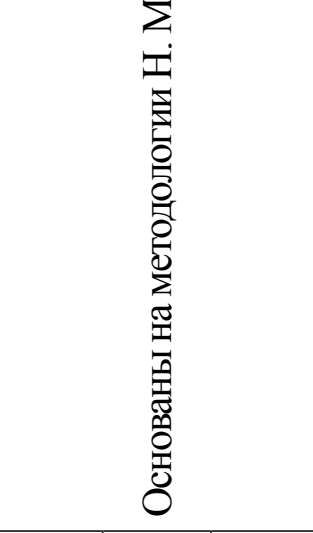 } & 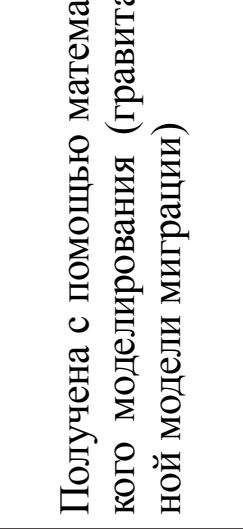 & 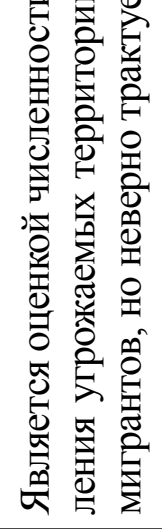 \\
\hline & 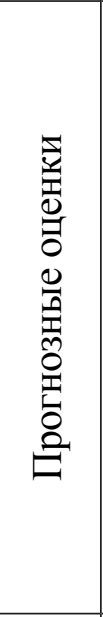 & 1 & 1 & 1 & 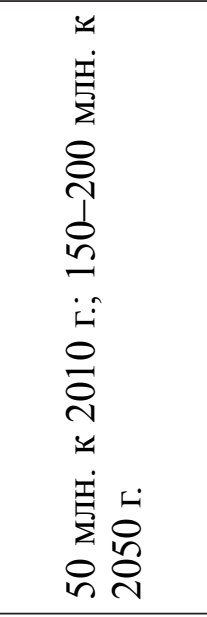 & 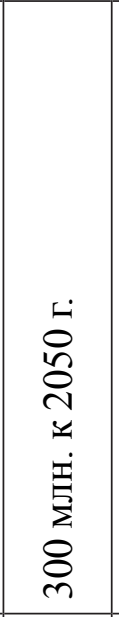 & 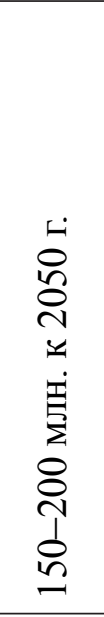 & 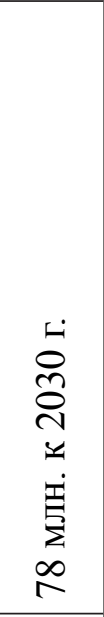 & 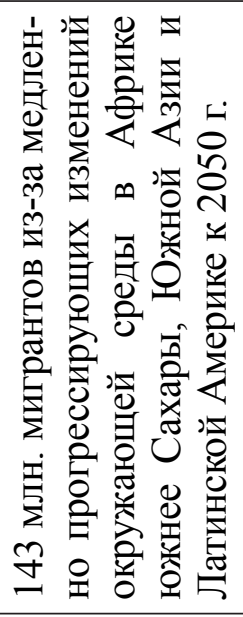 & 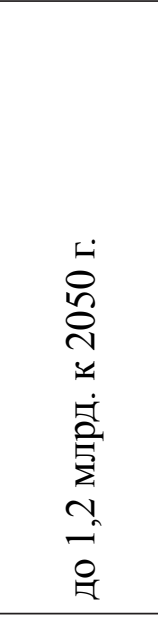 \\
\hline & 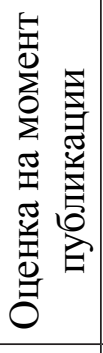 & 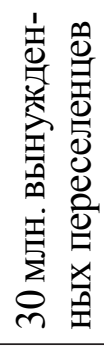 & 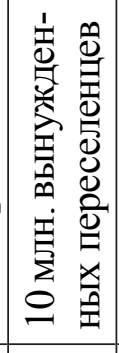 & 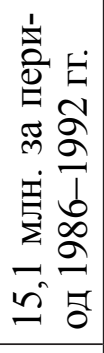 & 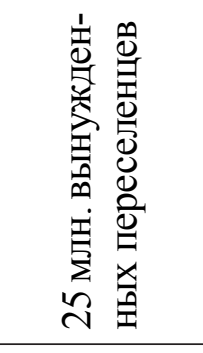 & 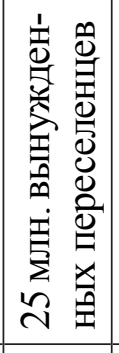 & 1 & 1 & 1 & 1 \\
\hline & 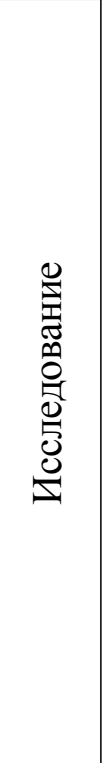 & 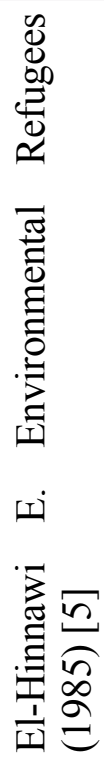 & 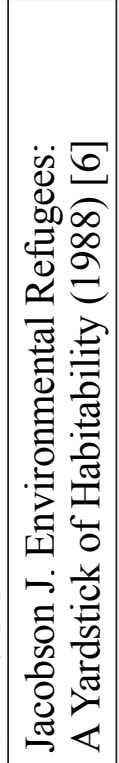 & 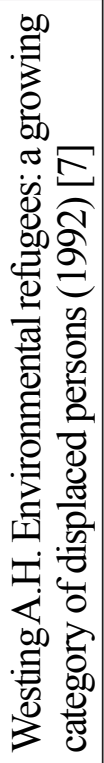 & 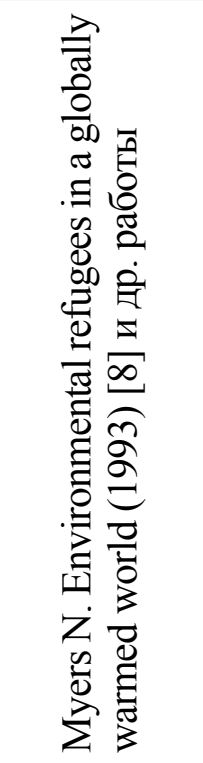 & 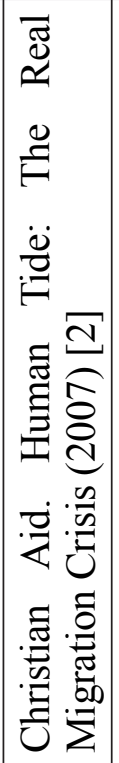 & 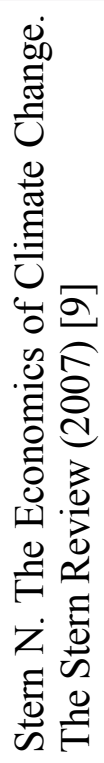 & 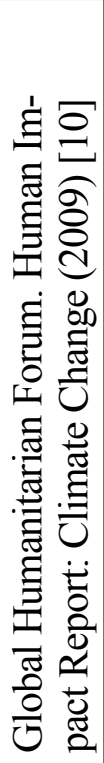 & 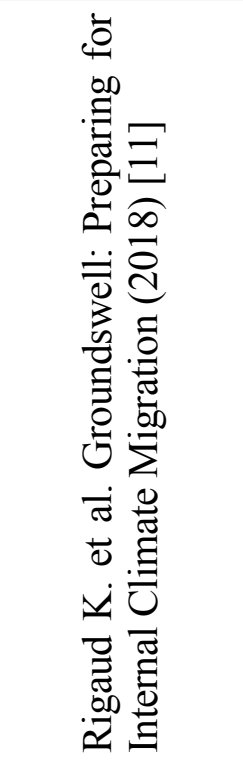 & 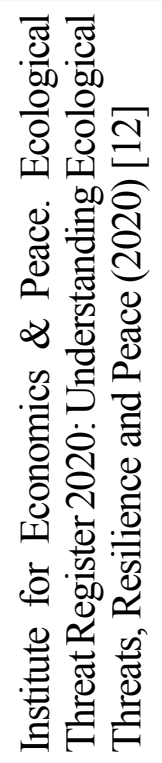 \\
\hline
\end{tabular}


ций. Из-за их территориально ограниченной юрисдикции затруднен сбор данных о международных миграциях, в том числе не достаточно данных, чтобы подтвердить или опровергнуть теории о связи климатической миграции и конфликтов. Кроме того, сбор статистических данных крайне затруднен в регионах, где уже происходит вооруженный конфликт, который мог быть усугублен климатической миграцией (например, Сирия [14]). С другой стороны, получить полные данные о внутренних миграциях проблематично, поскольку такие перемещения обычно не требуют оформления специальных документов.

6. Поскольку данные о мелких опасных природных явлениях зачастую не собираются на местном уровне и не попадают в отчетность, численность климатических мигрантов может быть недоучтена (даже если учет охватывает только вынужденные перемещения $)^{6}$. Например, согласно методологии IDMC, события, приведшие к перемещению менее 100 тыс. человек, являются мелкими и средними ${ }^{7}$.

7. На методологическом уровне в статистике отсутствует какой-либо подход к определению и учету населения, «попавшего в ловушку» климатических изменений (trapped populations) [15]. Эти люди не являются мигрантами, поскольку не могут покинуть неблагоприятную среду, но они могут быть более уязвимы перед лицом деградации окружающей среды, поскольку вынуждены оставаться на угрожаемой территории часто по причине бедности, которая только усугубляется по мере изменения климата.

Таким образом, первичные данные о численности климатических мигрантов являются неполными и фрагментарными. В качестве источников первичных данных можно назвать следующие (см. табл. 2).

Также в последние 10-15 лет было создано несколько баз вторичных данных о климатической миграции. Наиболее крупными являются следующие проекты (см. табл. 3).
Оценки численности климатических мигрантов, в том числе прогнозные оценки, предлагаемые разными исследователями (см. табл. 1), в значительной мере зависят от используемых ими методов. Э. Пиге выделил шесть типов методологических подходов к изучению миграций, связанных с изменением климата и окружающей среды [18] (табл. 4).

Согласно подсчетам МОМ, распределение методов, использованных в практических исследованиях (case studies) по миграции, вызванной изменениями окружающей среды (environmental migration), за 2017 г. отражено на рис. 1.

Выводы и обсуждение. Представляется, что в целях совершенствования количественных оценок климатической миграции необходимо, с одной стороны, совершенствование систем и методов сбора первичных статистических данных и, с другой стороны, комплексное применение различных методов ее изучения, поскольку ни один из имеющихся на сегодняшний день подходов не свободен от своих недостатков, как показал проведенный анализ. Работа может вестись по следующим направлениям.

1. Разработка и утверждение единого методологического подхода к определению и классификации климатических миграций. Таким образом, станет возможным обеспечение сопоставимости статистических данных, поступающих из разных стран и от различных международных организаций. При этом необходим раздельный учет вынужденных миграций (из-за внезапных стихийных бедствий) и добровольных миграций (из-за медленно прогрессирующего ухудшения условий окружающей среды).

2. Совершенствование систем статистического учета в развивающихся странах при содействии международных организаций (агентств ООН). На сегодняшний день 95\% всех вынужденных переселений по причине природных катастроф приходится на страны с низким и средним уровнем дохода (по клас-

6 Global Report on Internal Displacement 2018 [Electronic resource] // Internal Displacement Monitoring Center. URL: https://www.internal-displacement.org/global-report/grid2018/ (date accessed: 15.07.2021).

7 Methodological annex [Electronic resource] // Internal Displacement Monitoring Center. URL: https://www. internal-displacement.org/global-report/grid2018/downloads/report/2018-GRID-methodological-annex.pdf (date accessed: 15.07.2021). 


\section{Источники первичных данных о климатической миграции (составлено авторами)} Sources of primary data on climate migration (compiled by the authors)

\begin{tabular}{|c|c|}
\hline Источник & Данные \\
\hline $\begin{array}{l}\text { Статистика, собираемая } \\
\text { национальными органами } \\
\text { власти }\end{array}$ & $\begin{array}{l}\text { Данные о численности лиц, эвакуированных из-за стихийных } \\
\text { бедствий }\end{array}$ \\
\hline $\begin{array}{l}\text { Данные неправительствен- } \\
\text { ных организаций }\end{array}$ & $\begin{array}{l}\text { Информация от гуманитарных организаций, оказывающих по- } \\
\text { мощь населению в случае стихийных бедствий }\end{array}$ \\
\hline Данные визовых служб & $\begin{array}{l}\text { Информация о количестве гуманитарных виз, выданных в свя- } \\
\text { зи со стихийными бедствиями (напр., в США, Бразилии, Ар- } \\
\text { гентине, Мексике). Позволяет получить некоторые данные о } \\
\text { международной климатической миграции }\end{array}$ \\
\hline $\begin{array}{l}\text { Специальный проект MOM } \\
\text { (Displacement }^{\text {Matrix) }}{ }^{8}\end{array}$ & $\begin{array}{l}\text { Данные, собираемые МОМ, о численности внутренне переме- } \\
\text { щенных лиц9 , в том числе из-за стихийных бедствий }\end{array}$ \\
\hline Большие данные (big data) & $\begin{array}{l}\text { Данные мобильных телефонов, социальных сетей, на основе } \\
\text { которых можно определить, куда перемещались пользователи } \\
\text { после стихийных бедствий [16;17], а также спутниковые изоб- } \\
\text { ражения }{ }^{10} \text {. }\end{array}$ \\
\hline \multirow{3}{*}{$\begin{array}{l}\text { Некоторые региональные } \\
\text { проекты агентств ООН }\end{array}$} & $\begin{array}{l}\text { Информация о численности климатических мигрантах в стра- } \\
\text { нах, охваченных проектами: }\end{array}$ \\
\hline & $\begin{array}{l}\text { 1. Migration, Environment and Climate Change: Evidence for } \\
\text { Policy (MECLEP) }{ }^{11} \text { : Вьетнам, Гаити, Доминиканская Республи- } \\
\text { ка, Кения, Маврикий, Папуа-Новая Гвинея; }\end{array}$ \\
\hline & $\begin{array}{l}\text { 2. Pacific Climate Change and Migration (РССМ) }{ }^{12} \text { : Тувалу, Нау- } \\
\text { ру и Кирибати }\end{array}$ \\
\hline
\end{tabular}

8 Displacement Tracking Matrix [Electronic resource] // International Organization for Migration. URL: https:// dtm.iom.int/ (date accessed: 01.02.2021).

9 Внутренне перемещенные лица (Internally displaced persons) - лица или группы лиц, которые были вынуждены или обязаны внезапно покинуть свои дома или обычное место жительства в результате или во избежание последствий вооруженного конфликта, внутренней розни, нарушений прав человека или стихийных бедствий или антропогенных катастроф и которые не пересекли международно признанную государственную границу (Guiding Principles on Internal Displacement, annexed to United Nations Commission on Human Rights, Report of the Representative of the Secretary-General, Mr Francis M. Deng, Submitted Pursuant to Commission Resolution 1997/39, Addendum (11 February 1998) UN Doc E/CN.4/1998/53/Add.2, 6).

10 Migration, Environment and Climate Change: Evidence for Policy (MECLEP) [Electronic resource] // International Organization for Migration. URL: https:/environmentalmigration.iom.int/projects/migration-environmentand-climate-change-evidence-policy-meclep (date accessed: 06.07.2021).

11 Pacific Islanders Faced with Migration Can Benefit from Paris Agreement [Electronic resource] // United Nations Climate Change. URL: https://unfccc.int/news/pacific-islanders-faced-with-migration-can-benefit-from-paris-agreement (date accessed: 06.07.2021).

12 Global Internal Displacement Database [Electronic resource] // Internal Displacement Monitoring Center. URL: https://www.internal-displacement.org/database (date accessed: 15.07.2021). 
Некоторые базы вторичных данных о климатической миграции (составлено авторами) Some databases of secondary data on climate migration (compiled by the authors)

\begin{tabular}{|c|c|}
\hline База & Данные \\
\hline \multirow{3}{*}{ 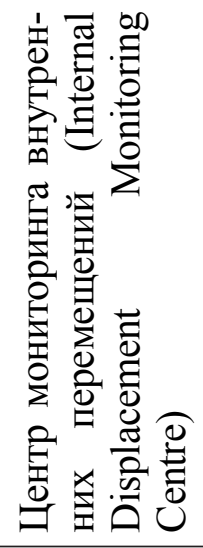 } & $\begin{array}{l}\text { 1. Глобальная база данных о численности внутренне перемещенных лиц (Global } \\
\text { Internal Displacement Database) }{ }^{13} \text { в в том числе из-за природных катастроф. Агре- } \\
\text { гирует данные, полученные от МОМ, Международного красного креста, Управ- } \\
\text { ления ООН по координации гуманитарных вопросов, национальных органов } \\
\text { власти, неправительственных организаций и средств массовой информации }\end{array}$ \\
\hline & $\begin{array}{l}\text { 2. Модель, позволяющая оценивать риск перемещения из-за природных катаст- } \\
\text { роф в будущем (Global Displacement Risk Model) }{ }^{14} \text {. Основана на прогнозах буду- } \\
\text { щих опасных природных явлений, численности населения угрожаемых терри- } \\
\text { торий, вероятности разрушения жилых домов и др. элементов инфраструктуры }\end{array}$ \\
\hline & 3. Ежегодные оценочные доклады (Global Report on Displacement) ${ }^{15}$ \\
\hline \multirow{3}{*}{ 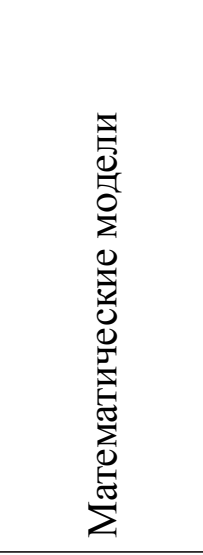 } & $\begin{array}{l}\text { Позволяют прогнозировать численность мигрантов и другие последствия изме- } \\
\text { нения климата в зависимости от сценариев потепления RCP: }\end{array}$ \\
\hline & $\begin{array}{l}\text { 1. Проект HELIX (High-End Climate Impacts and Extremes) }{ }^{16} \text {. Позволяет оценить } \\
\text { последствия изменения климата в различных регионах мира при различных } \\
\text { сценариях потепления }\end{array}$ \\
\hline & $\begin{array}{l}\text { 2. Доклад Всемирного банка Groundswell: Preparing for internal climate migration } \\
\text { [11]. Три варианта прогноза численности внутренней миграции из-за медленно } \\
\text { прогрессирующих изменений окружающей среды в трех регионах мира (Афри- } \\
\text { ке южнее Сахары, Южной Азии и Латинской Америке) до } 2050 \text { г. на основе гра- } \\
\text { витационной модели миграции в зависимости он сценариев изменения климата } \\
\text { и социально-экономического развития }\end{array}$ \\
\hline \multirow{4}{*}{ 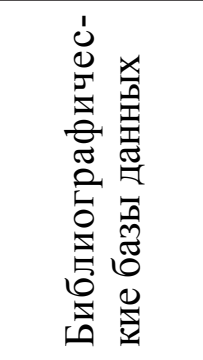 } & 1. Environmental Migration Portal Международной организации по миграции ${ }^{17}$ \\
\hline & 2. База данных CLIMIG при Университете Невшателя (Швейцария) ${ }^{18}$ \\
\hline & 3. Обсерватория Уго при Льежском университете (Бельгия) $)^{19}$ \\
\hline & $\begin{array}{l}\text { 4. Рабочая группа по изменению климата и миграции при Глобальном информа- } \\
\text { ционном партнерстве по миграции и развитию (Global Knowledge Partnership on } \\
\text { Migration and Development, KNOMAD) }{ }^{20} \text { и др. }\end{array}$ \\
\hline
\end{tabular}

13 Global Internal Displacement Database [Electronic resource] // Internal Displacement Monitoring Center. URL: https://www.internal-displacement.org/database (date accessed: 15.07.2021).

14 Global Displacement Risk Model [Electronic resource] // Internal Displacement Monitoring Center. URL: https://www.internal-displacement.org/database/global-displacement-risk-model (date accessed: 15.07.2021).

15 Global Report on Internal Displacement 2021 [Electronic resource]// Internal Displacement Monitoring Center. URL: https://www.internal-displacement.org/global-report/grid2021/ (date accessed: 15.07.2021).

16 HELIX Project (High-End Climate Impacts and Extremes) [Electronic resource]. URL: https://helixclimate.eu/ (date accessed: 15.07.2021).

17 IOM's Environmental Migration Portal [Electronic resource] // International Organization for Migration. URL: https://environmentalmigration.iom.int/research-database (date accessed: 15.07.2021).

18 CLIMIG database [Electronic resource]. URL: https://climig.com/climig-database/ (date accessed: 15.07.2021).

19 The Hugo Observatory [Electronic resource] // Université de Liège. URL: https://www.hugo.uliege.be/ $\mathrm{cms} / \mathrm{c} 4655083 / \mathrm{en} /$ hugo (date accessed: 15.07.2021).

20 Environmental change and migration [Electronic resource] // Global Knowledge Partnership on Migration and Development (KNOMAD). URL: https://www.knomad.org/thematic-working-group-single/9\#publications (date accessed: 15.07 .2021$)$. 


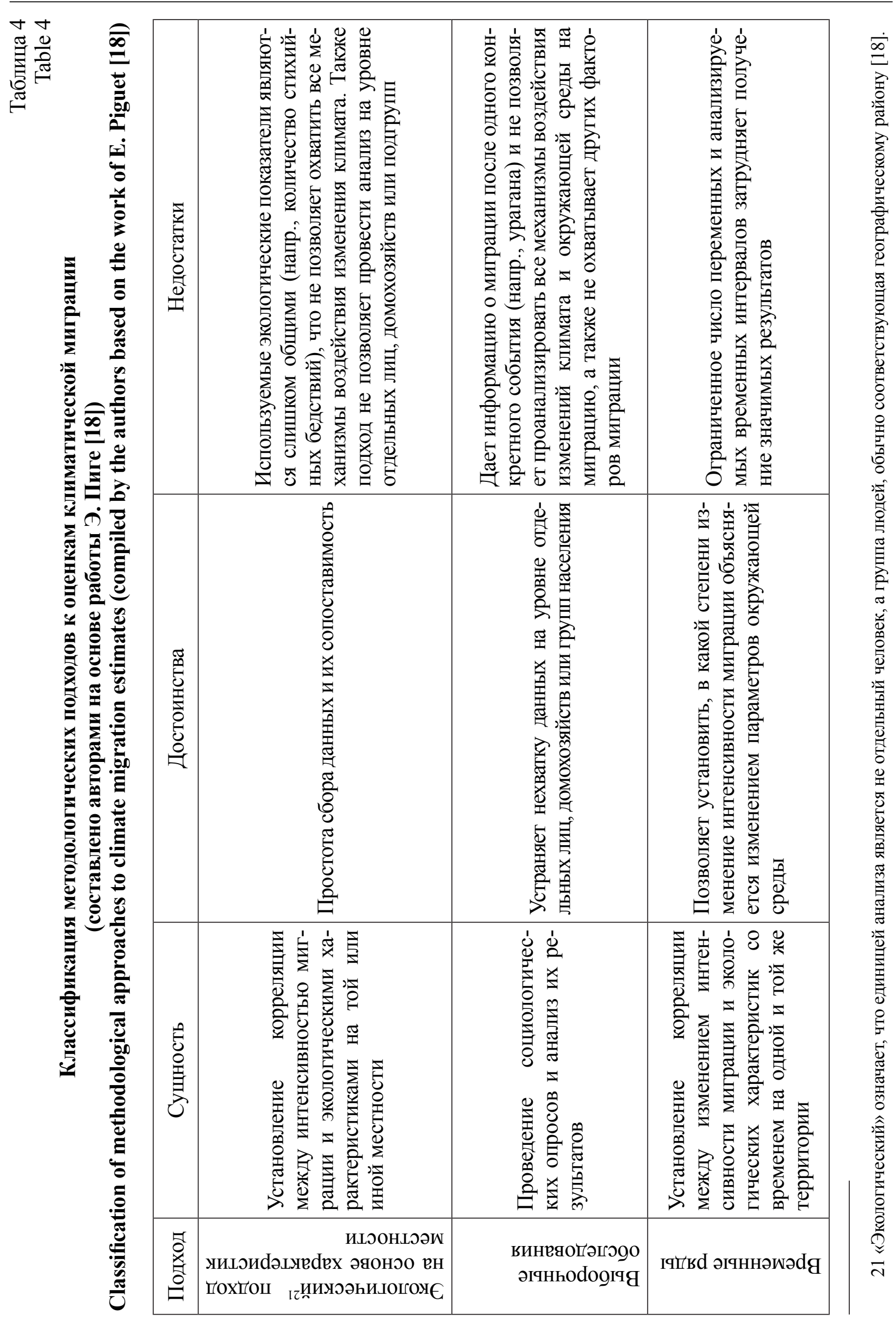




\begin{tabular}{|c|c|c|c|}
\hline \multirow[t]{4}{*}{ 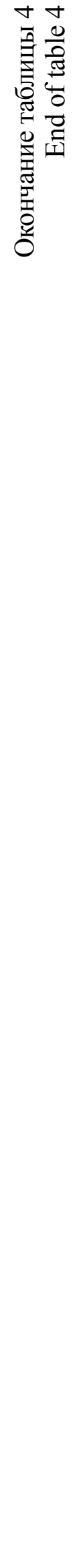 } & 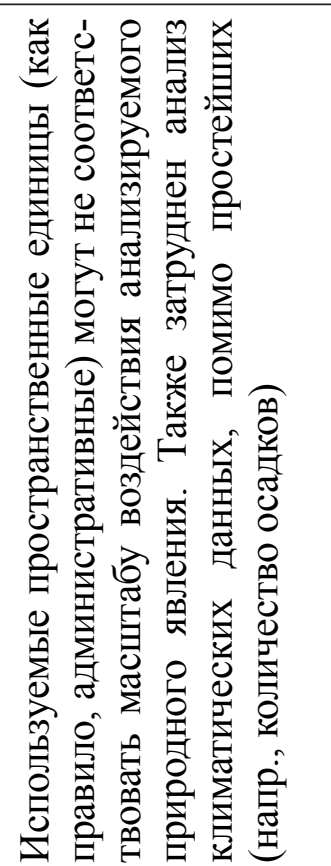 & 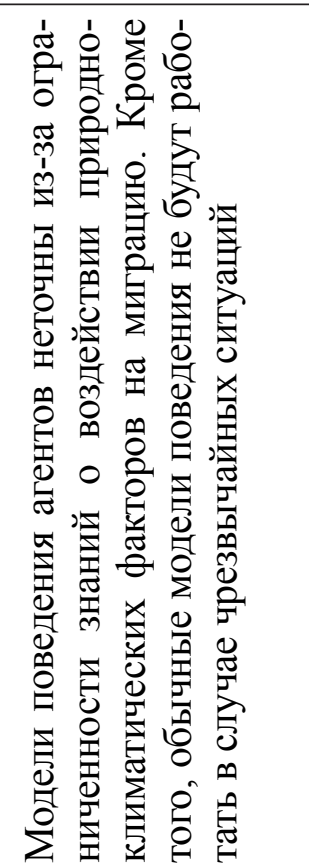 & 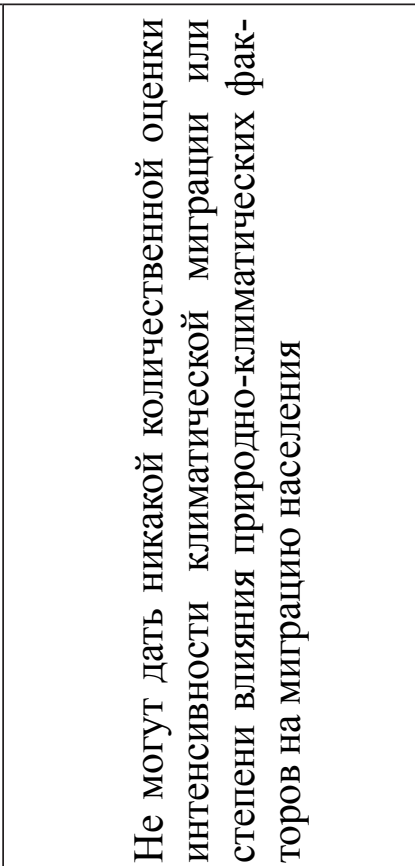 \\
\hline & 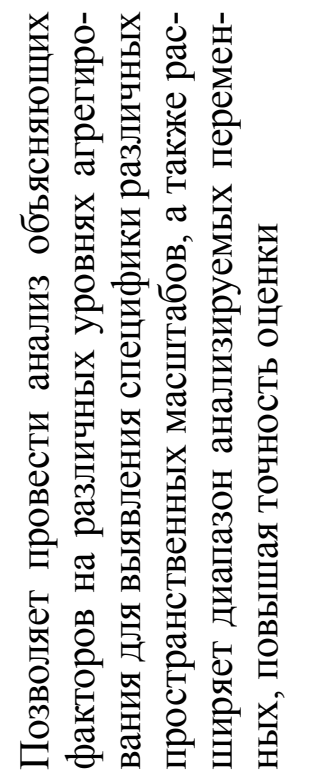 & 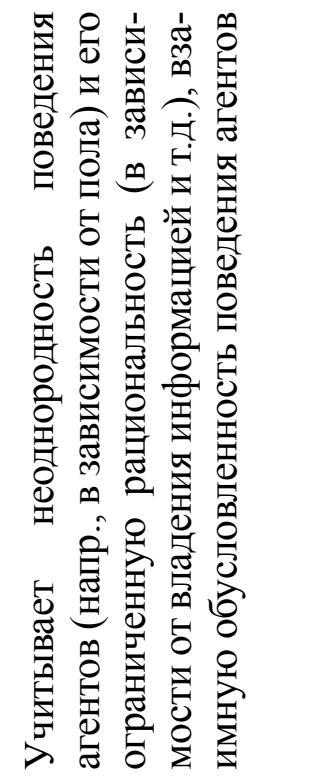 & 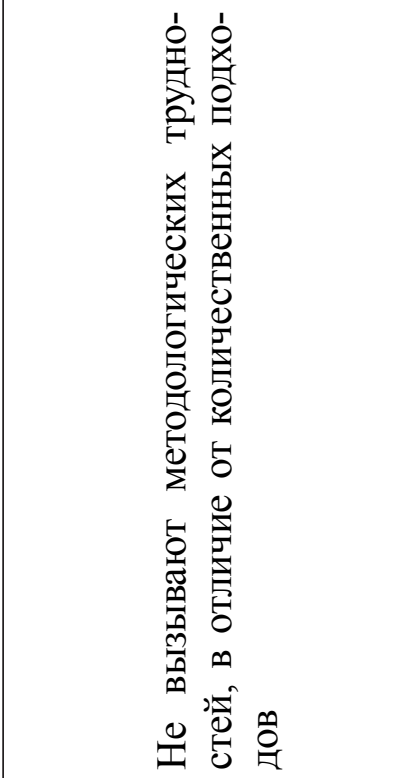 \\
\hline & 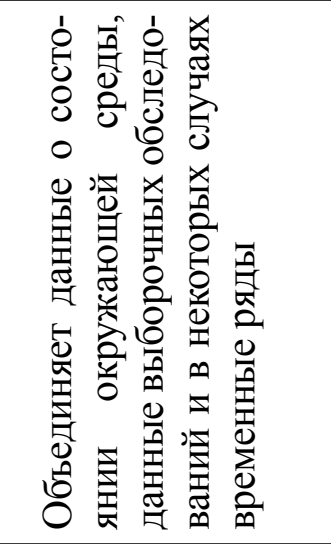 & 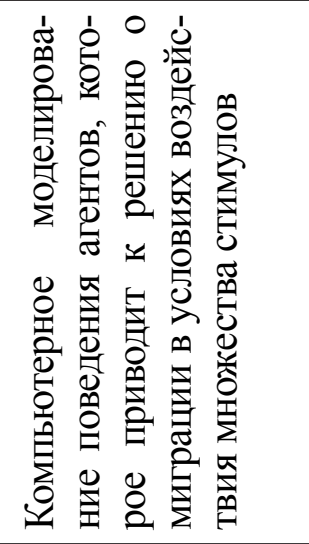 & 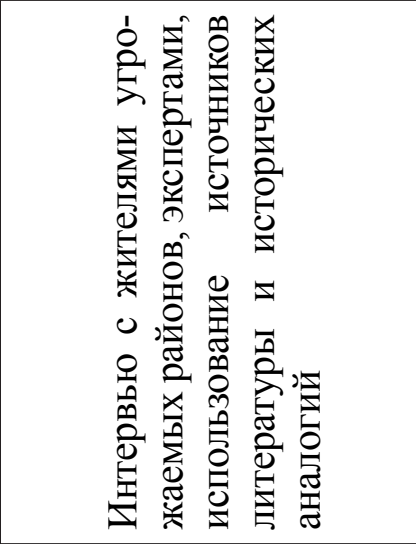 \\
\hline & 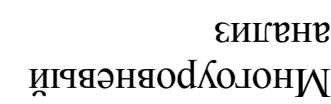 & $\begin{array}{r}\text { әинеяодигәгок } \\
\text { әонцнәл }\end{array}$ & 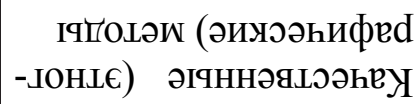 \\
\hline
\end{tabular}


сификации Всемирного банка) ${ }^{22}$, в то же время подавляющее большинство исследований и инициатив в области климатической миграции осуществляется в странах «глобального севера» [19]. Статистические службы многих развивающихся стран не имеют ресурсов для точного отслеживания всех внутренних перемещений, а климатическая миграция чаще всего является внутренней.

3. Проведение лонгитюдных наблюдений в «горячих точках», где численность климатических мигрантов и населения, проживающего на угрожаемых территориях, особенно велика. Это позволит получить более полную и более достоверную картинку климатической миграции: определить, какие группы населения более подвержены ее риску (каковы их демографические и социально-экономические характеристики), и что происходит с мигрантами после переселения (куда они перемеща- ются, как долго остаются вне своего постоянного места жительства, какая доля мигрантов возвращается домой, совершают ли они новые миграции в дальнейшем и куда направляются и т.д.). Эта информация крайне важна для разработки мер миграционной и экологической политики в таких регионах и принятия местными органами власти соответствующих управленческих решений. Кроме того, без нее невозможно применение новых методов исследования климатической миграции, таких как агентное моделирование.

4. Применение и совершенствование инновационных методов сбора данных и количественной оценки, в том числе основанных на «больших данных» от операторов сетей мобильной связи, социальных сетей, данных спутникового наблюдения и т.д. Это позволит получить более детальную информацию, когда ресурсы национальных служб статис-

\section{2 исследования за 2017 г.}

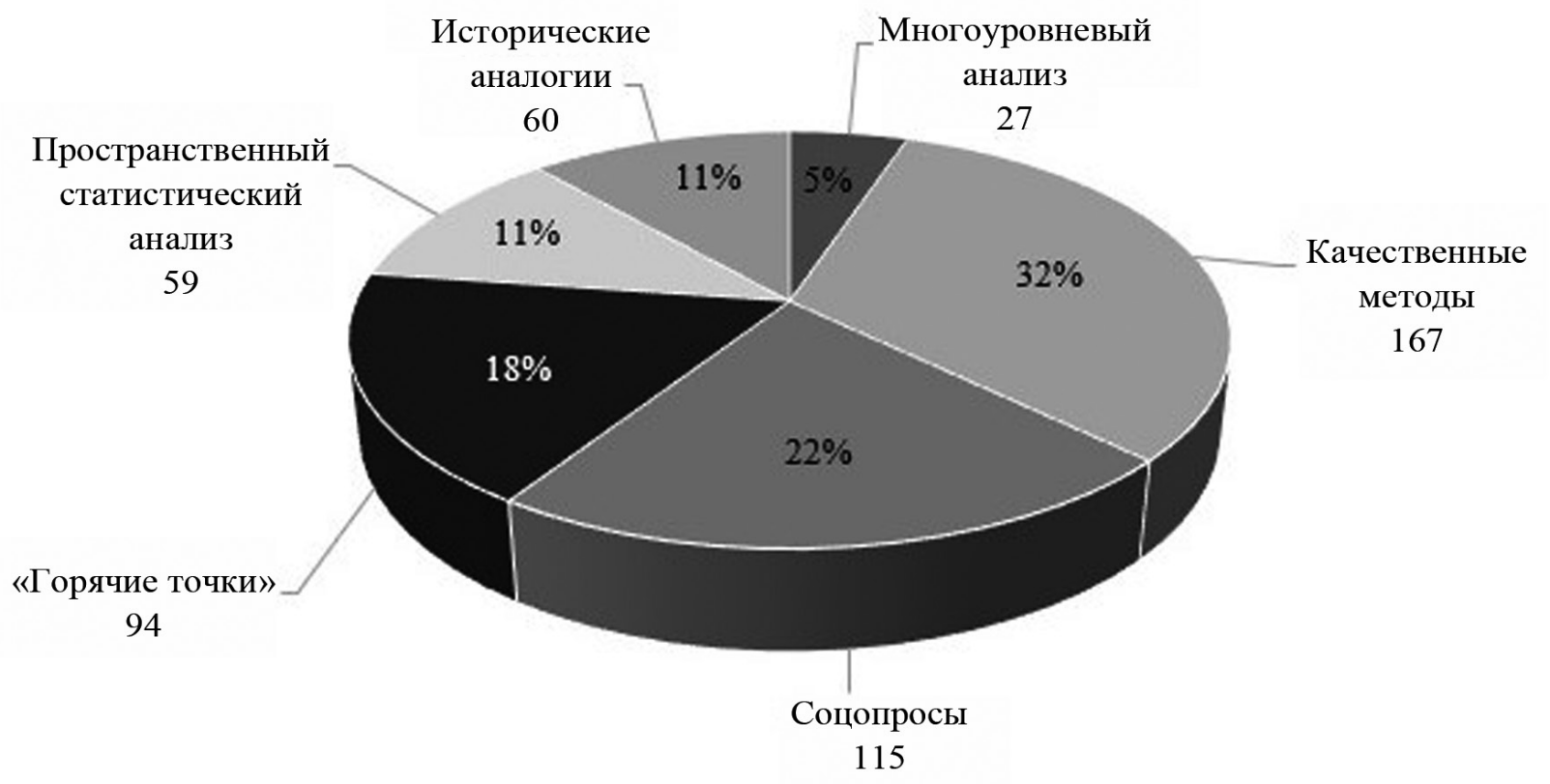

Рис. 1. Распределение исследований миграции,

вызванной изменениями окружающей среды, по использованным методам ${ }^{23}$

Fig. 1. Distribution of studies of migration caused by environmental changes according to the methods used

22 Global Internal Displacement Database [Electronic resource] // Internal Displacement Monitoring Center. URL: https://www.internal-displacement.org/database (date accessed: 15.07.2021).

23 Case Studies, Methods and Environmental Migration [Electronic resource] // Migration Data Portal. International Organization for Migration. URL: https://migrationdataportal.org/infographic/case-studies-methods-and-environmentalmigration (date accessed: 01.02.2021). 
тического наблюдения не позволяют отследить все перемещения, особенно перемещения на небольшие расстояния внутри страны или в приграничных районах.

5. Проведение исследований с применением комплексных методов количественной оценки климатической миграции. Проведенный нами анализ показал, что ни один из выработанных на сегодняшний день подходов не свободен от своих недостатков, поэтому применение нескольких методов позволит сократить количество «слепых пятен» в исследованиях и избежать неверной трактовки полученных результатов. Ярким примером тому может служить распространенное и по сей день невольное заблуждение детерминистского подхода, в рамках которого климатические изменения рассматривались как единственный фактор миграции и к числу мигрантов относилось все население угрожаемых территорий.

\section{Список источников}

1. Gemenne F. How they became the human face of climate change. Research and policy interactions in the birth of the 'environmental migration' concept. Piguet E. et al. (eds). Migration and climate change. Cambridge University Press, 2011. 354 p.

2. Christian Aid. Human tide: The real migration crisis. London: Christian Aid, 2007. 50 p.

3. Friends of the Earth. A Citizens Guide to Climate Refugees. Melbourne, Australia: Friends of the Earth, 2005. 13 p.

4. International Organization for Migration. Glossary on Migration. Geneva, Switzerland: International Organization for Migration, 2019. $233 \mathrm{p}$.

5. El-Hinnawi E. Environmental Refugees. Nairobi: UNEP, 1985. 41 p.

6. Jacobson J. Environmental Refugees: AYardstick of Habitability. Bulletin of Science, Technology and Society. 1988. Vol. 8, Issue 3. Pp. 257-258.

7. Westing A.H. Environmental refugees: a growing category of displaced persons. Environmental Conservation. 1992. Vol. 19. №3. Pp.201-207.

8. Myers N. Environmental refugees in a globally warmed world. BioScience. 1993. Vol. 43. №11. Pp. 752-761.
9. Stern N., Stern N.H. The economics of climate change: the Stern review. London: Cambridge University Press, 2007. 662 p.

10. Annan K. et al. Human Impact Report: Climate Change - The Anatomy of a Silent Crisis. Geneva: Global Humanitarian Forum, 2009. $124 \mathrm{p}$.

11. Rigaud K., de Sherbinin A., Jones B., Bergmann J., Clement V., Ober K., Schewe J., Adamo S., McCusker B., Heuser S., Midgley A. Groundswell: Preparing for Internal Climate Migration. Washington, DC: The World Bank, 2018. $222 \mathrm{p}$.

12. Institute for Economics \& Peace. Ecological Threat Register 2020: Understanding Ecological Threats, Resilience and Peace. Sydney, 2020.91 p.

13. Lukyanets A. S., Ryazantsev S. V., Maksimova A. S., Moiseeva E.M., Manshin R. V. Theoretical, methodological and statistical problems of studying environmental migration. Amazonia Investiga. 2019. Vol. 8. №19. Pp. 227-236.

14. Kelley C. et al. Climate change in the Fertile Crescent and implications of the recent Syrian drought. Proceedings of the National Academy of Science. 2015. Vol. 112. №11. Pp. 3241-3246.

15. Foresight. Migration and global environmental change, final project report. London: The Government Office for Science, 2011. 237 p.

16. Bengtsson L., Lu X., Thorson A., Garfield R., von Schreeb J. Improved Response to Disasters and Outbreaks by Tracking Population Movements with Mobile Phone Network Data: A Post-Earthquake Geospatial Study in Haiti. PLoS Medicine. 2011. Vol. 8. Issue 8.

17. Xin Lu, Wrathall D.J., Sundsoy P.R., Nadiruzzaman E. W., Asif Iqbal T. Q., Tatem A., Canright G., Engø-Monsen K., Bengtsson L. Unveiling hidden migration and mobility patterns in climate stressed regions: A longitudinal study of six million anonymous mobile phone users in Bangladesh. Global Environmental Change. 2016. Vol. 38. Pp. 1-7.

18. Piguet E. Linking climate change, environmental degradation, and migration: a methodological overview. Wiley Interdisciplinary Reviews: Climate Change. 2010. Vol. 1. Issue 4. Pp. 517-524.

19. Ionesco D., Mokhnacheva D., Gemenne F. The Atlas of Environmental Migration. New York: Routledge, 2017.368 p. 


\section{References}

1. Gemenne F. How they became the human face of climate change. Research and policy interactions in the birth of the 'environmental migration' concept. Piguet E. et al. (eds). Migration and climate change. Cambridge University Press, 2011. $354 \mathrm{p}$.

2. Christian Aid. Human tide: The real migration crisis. London: Christian Aid, 2007. 50 p.

3. Friends of the Earth. A Citizens Guide to Climate Refugees. Melbourne, Australia: Friends of the Earth, 2005. 13 p.

4. International Organization for Migration. Glossary on Migration. Geneva, Switzerland: International Organization for Migration, 2019. $233 \mathrm{p}$.

5. El-Hinnawi E. Environmental Refugees. Nairobi: UNEP, 1985. 41 p.

6. Jacobson J. Environmental Refugees: AYardstick of Habitability. Bulletin of Science, Technology and Society. 1988. Vol. 8, Issue 3. Pp. 257-258.

7. Westing A.H. Environmental refugees: a growing category of displaced persons. Environmental Conservation. 1992. Vol. 19. №3. Pp. 201-207.

8. Myers N. Environmental refugees in a globally warmed world. BioScience. 1993. Vol. 43. №11. Pp. 752-761.

9. Stern N., Stern N.H. The economics of climate change: the Stern review. London: Cambridge University Press, 2007. 662 p.

10. Annan K. et al. Human Impact Report: Climate Change - The Anatomy of a Silent Crisis. Geneva: Global Humanitarian Forum, 2009. $124 \mathrm{p}$.

11. Rigaud K., de Sherbinin A., Jones B., Bergmann J., Clement V., Ober K., Schewe J., Adamo S., McCusker B., Heuser S., Midgley A. Groundswell: Preparing for Internal Cli- mate Migration. Washington, DC: The World Bank, 2018. 222 p.

12. Institute for Economics \& Peace. Ecological Threat Register 2020: Understanding Ecological Threats, Resilience and Peace. Sydney, 2020. 91 p.

13. Lukyanets A. S., Ryazantsev S. V., Maksimova A.S., Moiseeva E.M., Manshin R.V. Theoretical, methodological and statistical problems of studying environmental migration. Amazonia Investiga. 2019. Vol. 8. №19. Pp. 227-236.

14. Kelley C. et al. Climate change in the Fertile Crescent and implications of the recent Syrian drought. Proceedings of the National Academy of Science. 2015. Vol. 112. №11. Pp. 3241-3246.

15. Foresight. Migration and global environmental change, final project report. London: The Government Office for Science, 2011. 237 p.

16. Bengtsson L., Lu X., Thorson A., Garfield R., von Schreeb J. Improved Response to Disasters and Outbreaks by Tracking Population Movements with Mobile Phone Network Data: A Post-Earthquake Geospatial Study in Haiti. PLoS Medicine. 2011. Vol. 8. Issue 8.

17. Xin Lu, Wrathall D. J., Sundsoy P.R., Nadiruzzaman E.W., Asif Iqbal T.Q., Tatem A., Canright G., Engø-Monsen K., Bengtsson L. Unveiling hidden migration and mobility patterns in climate stressed regions: A longitudinal study of six million anonymous mobile phone users in Bangladesh. Global Environmental Change. 2016. Vol. 38. Pp. 1-7.

18. Piguet E. Linking climate change, environmental degradation, and migration: a methodological overview. Wiley Interdisciplinary Reviews: Climate Change. 2010. Vol. 1. Issue 4. Pp. 517-524.

19. Ionesco D., Mokhnacheva D., Gemenne F. The Atlas of Environmental Migration. New York: Routledge, 2017. 368 p.

Статья поступила в редакцию 01.09.2021; одобрена после рецензирования 15.09.2021; принята к публикачии 25.09.2021.

The article was submitted on 01.09.2021; approved after reviewing on 15.09.2021; accepted for publication on 25.09.2021. 


\section{ИНФОРМАЦИЯ ОБ АВТОРАХ}

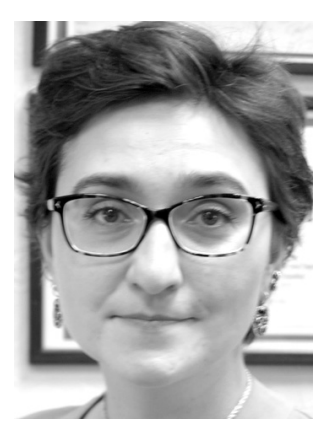

Моисеева Евгения Михайловна - аспирант, младший научный сотрудник Института демографических исследований Федерального научно-исследовательского центра Российской академии наук.

Россия, г. Москва, ул. Фотиевой, 6

Evgeniya M. Moiseeva - Graduate Student, Junior Researcher, Institute of Demographic Research of the Federal Research Sociological Center of the Russian Academy of Sciences.

6 Fotievoy st., bld. 1, Moscow, Russia 